\title{
Policy effects on charging behaviour of electric vehicle owners and on purchase intentions of prospective owners: Natural and stated choice experiments
}

\author{
Author(s) \\ Wolbertus, Rick; Kroesen, Maarten; van den Hoed, Robert; Chorus, Caspar G.
}

Publication date

2018

Document Version

Author accepted manuscript (AAM)

Published in

Transportation Research Part D: Transport and Environment

\section{License}

CC BY-ND

Link to publication

Citation for published version (APA):

Wolbertus, R., Kroesen, M., van den Hoed, R., \& Chorus, C. G. (2018). Policy effects on charging behaviour of electric vehicle owners and on purchase intentions of prospective owners: Natural and stated choice experiments. Transportation Research Part D: Transport and

Environment, 62, 283-297.

https://reader.elsevier.com/reader/sd/1D270EF13AAFA3C044B5BD70 B5F68172A52CF0675DE9312D7BFD3AEE0F7D3144C2D0F8CD90A F02F444F978660B63EF4B

If you believe that digital publication of certain material infringes any of your rights or (privacy) interests,

please let the Library know, stating your reasons. In case of a legitimate complaint, the Library will make the material inaccessible and/or remove it from the website. Please contact the library:

https://www.amsterdamuas.com/library/contact/questions, or send a letter to: University Library (Library of the University of Amsterdam and Amsterdam University of Applied Sciences), Secretariat, Singel 425, 1012 WP Amsterdam, The Netherlands. You will be contacted as soon as possible. 
Publishers' version available: R. Wolbertus, M. Kroesen, R. van den Hoed, C.G. Chorus (2018). Policy effects on charging behaviour of electric vehicle owners and on purchase intentions of prospective owners: Natural and stated choice experiments, Transportation Research Part D: Transport and Environment, 62, 283-297, https://doi.org/10.1016/j.trd.2018.03.012

\title{
Policy effects on charging behaviour of electric vehicle owners and on purchase intentions of prospective owners: Natural and stated choice experiments
}

\author{
Rick Wolbertus***, Maarten Kroesen*, Robert van den Hoed**, Caspar G. Chorus* \\ * Transport and Logistics Group, Department of Engineering Systems and Services, Faculty of \\ Technology, Policy and Management, Delft University of Technology, The Netherlands \\ ** Department of Urban Technology, Faculty of Technology, Amsterdam University of Applied \\ Sciences, The Netherlands \\ r.wolbertus@tudelft.nl
}

\begin{abstract}
Policy makers are looking for effective ways to promote the adoption of electric vehicles (EVs). Among the options is the roll-out and management of charging infrastructure to meet the EV drivers' refuelling needs. However, policies in this area do not only have a long-term effect on the adoption of EVs among prospective owners, they also have short-term impacts on the usage of public charging infrastructure among current EV owners and vice-versa. Presently, studies focusing on both effects simultaneously are lacking, missing out on possible cross-pollination between these areas. This study uniquely combines stated and revealed preference data to estimate the effect of particular policy measures aimed at $\mathrm{EV}$ adoption, on the one hand, and charging behaviour, on the other. Using a large dataset (1.7 million charging sessions) related to charging behaviour using public charging infrastructure in the Netherlands we quantify the effects of (i) daytime-parking (to manage parking pressure) and (ii) free parking (to promote purchase of EVs) policies on charging behaviour. To estimate the effects of these particular policies on EV purchase intentions, a stated choice experiment was conducted among potential EV-buyers. Results show that cross-pollinations between EV charging and adaptation policies exist and should be taken into account when designing policies for EV adoption.
\end{abstract}

(C) 2018. This manuscript version is made available under the CC-BY-NC-ND 4.0license. https://creativecommons.org/licenses/by-nc-nd/4.0/ 


\section{Introduction}

Electric vehicles (EVs) show great promise to help reduce emissions of greenhouse gases (Rangaraju, De Vroey, Messagie, Mertens, \& Van Mierlo, 2015) and local pollutants such as $\mathrm{NO}_{x}, \mathrm{SO}_{x}$ and $\mathrm{PM}$ (Razeghi et al., 2016). Despite these potential environmental benefits, the market share of electric vehicle is still relatively small al though it should be noted that sales are rapidly growing (International Energy Agency, 2016). Three major barriers have been identified that prevent large scale adoption of EVs: Range anxiety (Carley, Krause, Lane, \& Graham, 2013; Franke \& Krems, 2013b), high acquisition costs (Egbue \& Long, 2015; Hagman, Stier, \& Susilo, 2016) and a lack of (public) charging infrastructure (Egbue \& Long, 2015; Krupa et al., 2014). The first two barriers can be overcome by technological developments of batteries that drive down costs. In the last years the price perkWh storage has fallen rapidly (Nykvist \& Nilsson, 2015) and automakers are announcing affordable long range cars (200+ miles) for the period 2018-2022, signalling that EVs are becoming available fora wider range of consumers.

As EVs rely on a new refuelling network, the development of (public) charging infrastructure, or Electric Vehicle Supply Equipment (EVSE) infrastructure, is expected to follow the growth of EV sales. However, the deployment of public charging infrastructure faces a chicken-or-egg dilemma. With a low number of EVs on the market today, the business model of charging infrastructure is not viable (Madina, Zamora, \& Zabala, 2016; Schroeder \& Traber, 2012) and investments in this kind of charging infrastructure is trailing. The devel opment of a public charging infrastructure is however vital for early adopters of EVs especially for those that rely on on-street parking. This problem is particulary prevalent for those that live in multi-unit dwellings or in dense urban areas. Axsen \& Kurani (2012) estimate that in the United State only $50 \%$ of new vehicle buyers have direct access to minimal level 1 charging, although this varies from region to region. As home charging accounts for approximately $80 \%$ of all charging sessions (Idaho National Laboratory, 2015a), facilitating a public charging infrastructure in these areas should be a focus point in accelerating the EV adoption process (Hardman, Tal, et al., 2017).

As the market seems to fail, (local) governments step in to facilitate a public charge network; charging infrastructure development has been at the centre of attention for municipal policy makers to promote the adoption of EVs. They consider efficient planning of charging infrastructure to be important to meet drivers' refuelling needs (Frade, Ribeiro, Gonçalves, \& Antunes, 2011), and to satisfy interests of other stakeholders involved (Wirges, 2016). An increase in parking pressure, a problematic business case and potential grid overload are among the conflicts among stakeholders policy makers encounter when considering EVSE-policies (Bakker, Maat, \& van Wee, 2014). On the other hand, municipalities are considering other ways to promote EVs including measures such as free parking, access to HOV/Bus lanes and monetary incentives (Bjerkan, Nørbech, \& Nordtømme, 2016).

With an expanding market for EVs and EVSEs, interest in studies that measure the effectiveness of policies for EV adoption and of the deployment and management of charging infrastructure is growing (see next section for a review of this literature). However, available studies focus either on the (strategic level, long term) policy effects on EV adoption rates or on (tactical, short term) policy effects on current EV-owners' usage of public charging infrastructure, missing out on possible crosspollination between these polices. For example, implementation of highly restrictive policies 
regarding charging infrastructure may well have a (negative) impact on both charging behaviour of current EV-owners and EV-purchase intentions of current ICE-owners. Understanding these combined short and long run implications of charging infrastructure demand management is crucial for policy makers who want to avoid triggering unintended policy-effects, and more generally, design optimal policies.

This study fills this crucial knowledge gap by uniquely combining natural experiments and stated choice experiments to estimate the effects of charging policies on both charging behaviour of EVowners and EV adoption intentions of non-owners. More specifically, based on a large dataset on charging behaviour using public charging infrastructure in the Netherlands the effects of daytimeparking (to manage parking pressure) and free parking (to promote EVs) policies on charging behaviour are analysed. To estimate the effects of these policies on EV purchase intentions a stated choice experiment is conducted among car owners that rely on public infrastructure for charging their EVs. Section 2 presents a literature review and identifies the knowledge gaps to be filled with the research in this paper. In section 3 , the methodology of three experiments to investigate the effect of the two policies is outlined. This section includes a detailed description of the policies and how the experiments were set up and data were gathered. The results of these three experiments are presented and discussed in section 4 . The last section provides a conclusion and discusses the policy implication of the results.

\section{Literature review 2.1 Charging behaviour}

Research on charging behaviour has started with using travel patterns from ICE vehicles and tried to infer charging decisions from these patterns (Liu, 2012; Sathaye \& Kelley, 2013). Moving beyond this, exploratory work was done which tried to model the decision to start charging. Franke \& Krems (2013a) developed a model in which they incorporated the EV's range, range appraisal by users and specific mobility needs. Franke \& Krems (2013a) assumed that if the remaining range dropped below a certain comfortable level and the mobility needs could not be met, the driver would want to charge his car. However, during the evaluation of a trial, they observed high levels of habitual charging behaviour, which seemed to be more opportunity driven in ways comparable to mobile phone battery recharging (Franke \& Krems, 2013b). These findings have since then been confirmed in a growing body of literature around the world. Descriptive studies in The United states (Idaho National Laboratory, 2015b), Australia (Jabeen, Olaru, Smith, Braunl, \& Speidel, 2013; Speidel, Jabeen, Olaru, \& Harries, 2012), England (Robinson, Blythe, Bell, Hübner, \& Hill, 2013; Wardle, 2015), Canada (Toronto Atmospheric Fund, 2015), Ireland (Morrissey, Weldon, \& Mahony, 2016) and the Netherlands (Hoed, Helmus, Vries, \& Bardok, 2014; Spoelstra \& Helmus, 2015) confirm such behavioural patterns. In particular, these studies generally indicate two peaks in starts of charging sessions, one in the morning, reflecting "business charging", and one in the late afternoon, reflecting "home charging". These studies identified differences in charging behaviour by type of users (Helmus $\&$ van den Hoed, 2015) and described the influence of free charging and other price sensitivities (Idaho National Laboratory, 2015b; Wardle, 2015).

More recently, a body of work has focussed on assessing the determining factors that influence the decision to charge. Using stated preference techniques Wen, McKenzie \& Keith (2015) asked drivers 
about mid-trip charging and found that the State-of-Charge (SoC), dwell time and price are important factors that influence this decision. Jabeen et al. (2013) asked drivers to their most and least favourite option when presented with options for home, workplace and public charging. Time of day, time charging and price were varied across the categories. A strong preference was observed for home charging especially among solar panel owners. Latinopoulos, Sivakumar \& Polak (2017) provided additional insight to charging behaviour, by modelling in and out-of-home-charging. They show that out-home-charging is more common for those that have the opportunity to charge at work or when it is offered for free. Daina (2014) has looked at several factors that could influence the decision to delay charging allowing 'smart charging' technologies that could reduce the impact of EVs on the grid. Daina (2014) showed that EV users are willing to allow flexibility as long as this does not influence the range needed for the next trip.

Using revealed preference data Zoepf et al. (2013) looked at charging choices by PHEV drivers with a small battery pack. They found that the number of miles driven on electricity greatly increases if the PHEV is charged every time a car stops for more than 3 hours, an indication that the 'parking is charging' regime is an efficient mode. Using the same dataset as Zoepf et al. (2013) and a matching dataset with electric vehicle charging stations Yu \& MacKenzie (2016) examined charging location choices in more detail. Their results showed a better model fit, but similar conclusions were drawn from the data. Using data from full electric vehicles, Sun, Yamamoto, \& Morikawa (2016) studied fast charging choices in Japan. They found that users are willing to detour up to $1.75 \mathrm{~km}$ on working days and 750 meters on non-working days. A remarkable finding is that even at fast charging stations the SoC at which drivers initiate their charging sessions is on average over $50 \%$, this in contrast with the assumptions in many planning studies that fast charging is mainly done with low SoC (Shahraki, Cai, Turkay, \& Xu, 2015; Zhang, Shaffer, Brown, \& Samuelsen, 2015). More recently Xu et al. (2017) have looked at linkages between charging station location, timing and mode of charging. They estimated a joint charging mode and location model on actual charging sessions showing that the time has a strong correlation with mode and location and that a dense and free public charging infrastructure results in an increasing number of public charging sessions.

In sum, the charging behaviour literature has over time developed from modelling exercises, including those based upon ICE travel patterns, into more descriptive and explanatory empirical work, as real world charging data are becoming more and more available. Whereas earlier work was mostly focused on assessing the factors determining the decision to start charging, more recent (modelling) work has focussed on capturing heterogeneity across EV drivers using more sophisticated discrete choice models. The number of factors and model structures that have been considered is growing but still limited, and many factors that play a role on other than the starting-dimension of the charging behaviour (e.g. location, duration) have not yet been explored empirically. Finally, the effects of policies that were designed to influence charging behaviour have only been investigated in stated preference studies.

\subsection{EV purchase intentions and charging infrastructure}

A large and growing body of literature has investigated the factors that play a role in the EV purchase intention. Three recent literature reviews (Coffman, Bernstein, \& Wee, 2016; Liao, Molin, \& Wee, 2015; Rezvani, Jansson, \& Bodin, 2015) have analysed the findings from over 50 different studies. They find evidence that internal factors, the EV properties, especially range and price have a large 
effect on purchase intention. The evidence for external factors such as fuel prices and consumer characteristics is mixed. Especially in studies with revealed preference data these effects are found to be insignificant. Significant effects are found for financial policy measures (Hardman, Chandan, et al., 2017) which directly influence the internal factors of the car. Policy measures such as free parking (Cherchi, 2017; Fearnley, Pfaffenbichler, Figenbaum, \& Jellinek, 2015; Hoen \& Koetse, 2014) and access to HOV/Bus lines (Bjerkan et al., 2016; Chorus, Koetse, \& Hoen, 2013) have provided mixed evidence in support of a positive effect on EV purchase intention.

Although the need for public recharging is generally low, especially in multi-car households, if home charging is available (Jakobsson, Gnann, Plötz, Sprei, \& Karlsson, 2016), a lack of it would hamper market adoption. The number of studies that have taken into account the effect of charging structure on EV-purchase intentions is limited. The effects of (perceived) EVSE availability on stated purchase intentions have been assessed by studies of Carley et al. (2013) and Bailey, Miele \& Axsen (2015). Both studies show weak or no significant correlations between recalling public EVSEs and the willingness to buy an EV. More important was the possibility of installing charging equipment at home. These studies also showed that awareness of EVSEs is low at the time the surveys were taken, which was 2011 and 2013 respectively. In the first study only 12\% or respondents recalled having seen a public charger and in the second study only 18\%. More recently, Cherchi (2017) has taken into account charging infrastructure availability and other parking policies and found that availability did have a positive effect on purchase intention; this study however focussed on availability of charging infrastructure away from home. Ensslem, Jochem, Schäuble, \& Babrowski (2013) also find that interoperability across charging station and borders, especially in border regions, is mentioned as an important factor driving purchase decisions.

Gnann \& Plötz (2015) reviewed several studies that looked at the interaction with infrastructure and EV adoption. They compare various studies which al so looked at other AFVs such as natural gas and hydrogen and discussed the peculiarities of electric vehicles. They find that for a successful introduction infrastructure should be directly available, the business case for infrastructure has to viable on short or medium long term and fuel prices have to be below ICE alternatives. For the EV market they find that infrastructure should be more widespread because of longer refuelling times but that a large part of this could be dealt with due to the possibility to recharge at home.

A more top-down approach is adopted by a number of studies that use sales figures to assess the impact of charging infrastructure on the adoption of EVs. Comparing the adoption rates and their policy incentives across different countries, Sierzchula et al. (2014) found that charging station investments were twice as effective as tax benefits in promoting the sales of electric vehicles. Mersky, Sprei, Samaras \& Qian (2016) have looked at municipal and regional adoption rates in Norway and also found that charging infrastructure presence had a significant positive effect on the number of EV purchases. They do note that the direction of this correlation is difficult to determine as charging stations are also build in response to local EV demand. Li et al. (2017) try to address this problem by modelling network effects in the sales of EVs in 353 metropolitan areas in the United States. Taking these effects into account they still find that investing in charging infrastructure is twice as effective as direct financial incentives. These results are thus well in line with the findings of Sierzchula et al. (2014).

\subsection{Knowledge gaps and contributions}


In sum, a large number of studies have focussed on the factors, including policy interventions, that determine EV-purchase intentions, showing that the properties of EVs themselves play a dominant role. The role of charging infrastructure policies is still under debate, as stated preference studies find only small effects of actual availability of public infrastructure even though absence of a home charging opportunity is seen as a crucial obstacle. Revealed preference studies find positive effects but have difficulty determining the direction of causality when assessing the impact of public charging infrastructure on EV sales. However, the number of studies is growing, including comparisons with other AFVs; results presented in these studies provide preliminary evidence for a positive effect of charging infrastructure availability on EV sales. No specific studies were found that took into account the design of policies for optimizing the utilization of public charging infrastructure and their effects on EV-purchase intentions. The latter is vital especially for those prospective EVowners who live in urban environments without private parking facilities, as for them, charging at home in public is likely to be the dominant mode of charging.

This research contributes in three different ways to the current understanding of charging behaviour and $\mathrm{EV}$ purchase intention. The first contribution is to assess the effectiveness of certain policies that try to control charging behaviour; to this aim, we use a large dataset of actual charging sessions of public charging infrastructure, under different policy contexts. Secondly, using a stated preference experiment, evidence is provided for the importance of charging infrastructure availability on the purchase intention of EVs. The experiment focuses explicitly on those prospective owners who do not have private parking facilities (as is the case in many highly urbanized areas throughout the world), and therefore rely on on-street parking facilities and public charging infrastructure. This group has so far been ignored in the literature.

The last and main contribution of this study lies in combining and cross-linking charging behaviour control policies with purchase intention and $\mathrm{EV}$ purchase policies with charging behaviour.

Connections between these policy-and behavioural dimensions have so far not been made. A visual representation of the concept that is studied in this research is given in Figure 1, where dotted lines indicate the new area of research and solid lines the current state of the art.

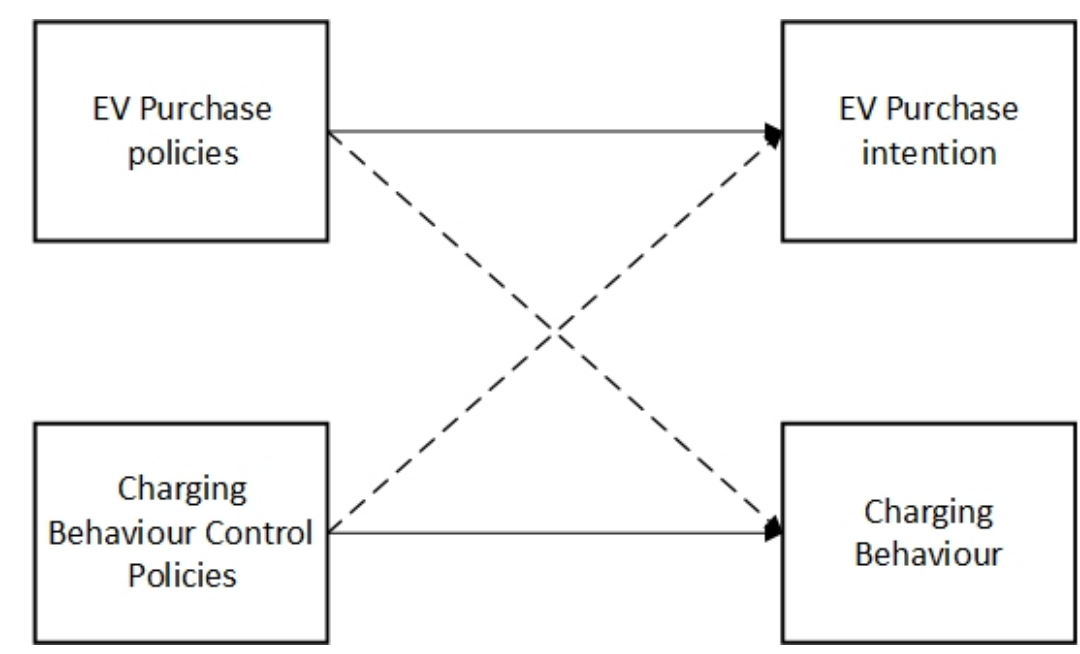

Figure 1 Model of policies influencing EV purchase intention and Charging Behaviour

To investigate these relationships, case studies of such policies are investigated in this paper. More specifically, we study a unique combination of three different experiments in which two policies are 
considered. These two particular policies are selected because they illustrate how policy makers at the local level are trying to deal with different interests of stakeholders. More specifically, following the framework developed in Figure 1, our case studies are interesting to consider because they concern policies that can simultaneously have desirable and unwanted side effects on EV purchase intentions and charging behaviour. Furthermore, the fact that these policies have al ready been implemented in the Netherlands at a relatively large scale provides the opportunity to systematically analyse these effects. Additionally, the chosen case studies are selected for providing us with very advantageous 'natural experiment' conditions for daytime charging-as well as with comparable conditions across four cities which allows us to control for many spatial-temporal effects for free parking. This combination of factors makes the two selected case studies ideal for investigating the impacts of local EV- and charging-related policies.

First, as a charging behaviour control policy, a daytime charging policy is investigated. This policy aims to reduce the impact of charging stations on parking pressure. This case study provides a good example of policies that are relevant in dense urban areas with a lot of on-street parking facilities. Moreover, it is a typical transition policy in which municipalities try to cope with interests of different actors, in this case the EV and non-EV driver. Literature in the EV adoption domain also suggests that perceived barriers in refuell ing behaviour can be an obstacle in purchasing an EV (Egbue \& Long, 2015) making it possible to investigate the conceptualised cross-link. The second case study concerns a free parking policy. Free parking is often mentioned and studied as an EV purchase policy for which the evidence is a mixed bag, this paper provides additional insight in the effect of this policy for prospective owners with private parking facility. The cross-link between EV purchase policies in charging behaviour is also relevant as evidence from the parking literature (Shoup, 2005) suggests that this policy can have an effect on the parking and charging behaviour of EV-owners.

\section{Methodology}

This paper estimates the effects of two local policies on charging behaviour and purchase intention: (1) daytime charging to alleviate parking pressure due to unoccupied parking spots at charging stations and (2) free parking for electric vehicles (while these are connected to the charging station) to promote the sales of electric vehicles. In the following, we will elaborate on these specific policies.

\subsection{Experiments}

\subsubsection{Daytime charging}

Municipalities are advised to exclusively reserve parking spots next to public charging stations to ensure availability for electric drivers. When charging stations are underutilised compared to average parking occupancy this can lead to increased parking pressure in neighbourhoods with relatively abundant charging infrastructure. To deal with this problem, municipalities can implement a daytime charging policy. Daytime charging implies that the parking spot next to a charging station is exclusively reserved for electric vehicles for the indicated part of the day. A street sign (see Figure 2) is put up to indicate the designated times. Beyond these hours both electric and gasoline driven cars are allowed to use the parking spot, in order to relieve parking pressure at the most strenuous times. 


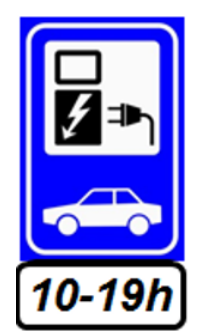

Figure 2 Street sign to indicate that parking spot is exclusively reserved for charging vehicles between 10:00 and 19:00

With regard to the effects on charging behaviour, it is expected that this policy will increase the difficulty of EV drivers to access charging stations after 19:00 as non-EV users can also park at these spots making. Occupation of the charging station is therefore expected to be lower in the hours beyond 19:00 at charging stations with the daytime charging policy implemented. Should this be the case, the policy has the intended effect of relieving parking pressure in the area surrounding the charging station. As a second-order effect on purchase intentions, it is assumed that the daytime restriction will reduce the purchase intention for $\mathrm{EV}$, since home charging availability is an important factor in EV adoption (Carley et al., 2013). Hence, if uncertainty arises about availability because of the daytime charging policy, this could reduce EV purchase intention.

The municipality of The Hague (The Netherlands) implemented daytime charging starting in January 2013 at charging stations in areas in which parking spot occupancy was over $90 \%$. In total, 79 charging stations were selected, but due to an unknown error at the municipal services, 20 charging stations did not receive a daytime charging sign; the resulting random assignment of policy-measures created the ideal conditions for a natural experiment. This is important, as it rules out potential endogeneity effects (e.g. policies being implemented in response to observed behaviour such as in this case, high on street parking rates); this allows for a clear identification of causality when studying policy effects on behaviour. Daytime charging was set between the periods 10:00 and 19:00.

Charging stations in areas with parking pressure below $90 \%$ remained exclusively available for EVs. By September 2015 the munici pality corrected the error and al so put up the road signs at the 20 charging stations that first did not have this sign installed.

The occupancy of the charging stations during and beyond the daytime charging times is compared, to estimate if the policy has an effect on charging station occupancy. Our analysis focuses on the increase in charging station occupancy after 19:00 as this is line with the policy. The increase between 19:00 and 0:00 is chosen as measurement value as profiles show that, on average, after 0:00 the increase in occupation is minimal. Using linear regression models the effect of the daytime charging policy is statistically evaluated while control ling for three factors: Spatial characteristics of the surroundings, if the charging station is in a paid parking area and the number of parking spots reserved alongside the station ( 1 or 2 ).

\subsubsection{Free Parking}

An often mentioned policy to increase EV sales is free parking for electric vehicles (Bjerkan et al., 2016; Sierzchula et al., 2014). Based on a literature overview, Liao et al. (2015) find, however, that the evidence for a positive effect of this policy is mixed. Despite the inconclusiveness of the currently 
available research it remains a popular incentive for municipalities to implement this policy, as it provides a direct and visible incentive for potential buyers. Parking literature suggests that a side effect of this policy could be that parking duration increases (Shoup, 2005). An increase in parking duration could lead to inefficient use of charging resources as longer connection times do not necessarily impose more charging. In turn high occupancy may increase difficulty of EV drivers to find a charging spot and may drive down business case due to lower daily usage.

Free parking policies can be executed in two different ways. First, free parking can be offered everywhere in a city for electric vehicle even when it is not charging. Second, free parking can be offered only when the EV is connected to a charging station. The second version is considered in the experiment that is evaluated, with the constraint that the policy only holds for on-street parking spots and not for parking garages. Note that the considered policy holds both for inhabitants and visitors. The expectations are that this policy results in an increase in the time that the EVs are connected to the charging station in line with current insights from 'regular' parking. This aspect will also hold for inhabitants as they do not have an incentive to move their car once it is fully charged as they have to move their car into a paid parking spot.

The city of Utrecht has implemented a free parking policy for EVs, which will be continued until at least the end of 2017. Free parking is only offered when the EV is actually connected to the charging station. Parking at regular parking spots requires paying a parking fee or having a parking permit. To assess if EV-connection duration is actually longer in paid parking areas were $\mathrm{EV}$ s are allowed to park for free we estimate an ordinal logistic regression model of (EV-) parking/connection duration. In this model we predict an (ordinalised) measure for parking duration in Utrecht as well as several other municipalities, while controlling for time and space differences for each charging session.

\subsubsection{Purchaseintention}

To estimate the impact of abovementioned policies on the purchase intention a stated choice survey was conducted. In this survey respondents were asked to make a choice among three types of vehicles (EV, PHEV and Conventional) each with a certain price and range. Each choice was made under a different policy setting. The policy setting included variations of the daytime charging and free parking policy and additionally included the placement strategy of the municipality. Figure 3 gives an example of the choice task that respondents faced.

\begin{tabular}{|ll|}
\hline & The policy has been set for the next 5 years as follows: \\
\hline Placement strategy: & The municipality places a charging station per new EV \\
\hline Parking tariff: & Free parking is offered while charging, regular fee applies when not connected \\
\hline Availability: & $\begin{array}{l}\text { Parking spot at the charging station is exclusively available between 8:00 and 20:00 } \\
\text { for EVs }\end{array}$ \\
\hline
\end{tabular}

\begin{tabular}{|l|c|c|c|}
\hline & Electric Vehicle & Plug-in Hybrid Vehicle & Conventional Vehicle \\
\hline Retail Price & $£ 20.000$ & $£ 30.000$ & $£ 20.000$ \\
\hline Electric Range & $500 \mathrm{~km}$ & $50 \mathrm{~km}$ & - \\
\hline
\end{tabular}

Choice: 
Policies were represented as context variables which were told to be valid for the 5 years to come and which were varied across choice sets (Molin \& Timmermans, 2010). Placement strategy was varied in which municipalities placed a charging station per every 1, 2 or 4 new EVs. Parking fee policy was noted as either being free, free while charging or with a regular tariff applied. The availability of the parking spot was noted as either exclusively available for EVs, or as daytime charging between 8:00 and 22:00, or as being al ways available for all type of vehicles. Retail prices for EVs and PHEVs were varied ( $€ 20 \mathrm{k}, € 25 \mathrm{k}$ and $€ 30 \mathrm{k}$ ); for the conventional vehicle these were held constant at $€ 20 \mathrm{k}$. Electric range for the EV $(200 \mathrm{~km}, 350 \mathrm{~km}, 500 \mathrm{~km})$ and the PHEV $(25 \mathrm{~km}, 50 \mathrm{~km}$, $75 \mathrm{~km}$ ) were also varied across alternatives. The experiment had a $3^{3}$ dimension for the policy context and $3^{4}$ dimension for the vehicle characteristics. Taguchi (1987) orthogonal arrays were used to develop the choice sets. The total of 81 choice sets were blocked by 3 policy designs to reduce the choice load for respondents. Each respondent was faced with 9 choice sets and thus 3 different policy scenarios. Respondents were also informed about other characteristics of the vehicles such as the gasoline range, fuel price per $\mathrm{km}$, road taxes and charging speed. A detailed list can be found in appendix A. Information was kept constant among the choice sets and represented at each choice.

To account for heterogeneity in preferences the data are analysed using mixed logit models (Train, 2009). The Bison Biogeme software package is used to this end (Bierlaire, 2003). Constants are estimated for the electric and conventional vehicle; the utility function of the plug-in hybrid vehicle includes both these constants. Policy variables are only included for the EV and PHEV utility functions as they do not apply to the conventional vehicle. Models were tested with 125 to 1000 Halton draws; estimates remained constant if the numbers of draws were increased.

\subsection{Data Collection}

\subsubsection{Daytime charging}

The effects on charging and parking behaviour of the daytime charging policy experiments are evaluated using data on charging sessions from public charging stations in The Hague, the Netherlands. Charging stations can be used by swiping a RFID card, identifying the user. Data is stored for each charging session and provided by several charging point operators to a central database. The data contains relevant information about the location and timing of the charging session and provides an anonymous code to identify the user.

The entire database contains 146,977 charging sessions in the city of The Hague during the period of January 2014 to September 2015. Additional information about which charging stations had daytime charging implemented at which time was provided by the municipality of The Hague. Selecting only charging stations that were eligible for the daytime charging policy (79 out of 392 in total) left 21.023 charging sessions. After filtering out sessions above $100 \mathrm{kWh}$ (as no cars have battery packs above $100 \mathrm{kWh}$ ) and sessions shorter than 1 minute, which both are considered as erroneous, 20,856 charging sessions remained for our empirical analyses. The data were then aggregated per charging station and hourly level for each weekday, to calculate the average occupancy rate of each charging station and the relative number of charging sessions per hour. Each charging station has two sockets, which implies that when only one of the sockets is used the occupancy ratio is $50 \%$. Average occupancy rate per hour is calculated from the date the charging station is first used until the set 
end-date of the dataset, 23:59 August 31st 2015. For the average occupation ratio only the weekdays are taken into account, as weekend charging can show very different behaviour and parking related problems are usually very different as well. Table 1 shows the descriptive statistics of the data presented for each of the groups.

Table 1 Descriptive statistics of charging stations

\begin{tabular}{|lll|}
\hline $\begin{array}{l}\text { Total } \\
\text { Policy }\end{array}$ & No. of charging stations \\
$\begin{array}{l}\text { Daytime parking } \\
\text { No daytime parking }\end{array}$ & 59 & \\
$\begin{array}{l}\text { Dedicated parking spots } \\
1\end{array}$ & 20 & \\
2 & 26 & \\
$\begin{array}{l}\text { Paid parking } \\
\text { Paid }\end{array}$ & 53 & \\
Free & 43 & \\
& 36 & \\
& & $23.00 \%$ \\
$\begin{array}{l}\text { Area Living (\% total buildings in } \\
\text { the sub-district) }\end{array}$ & $48.58 \%$ & $10.79 \%$ \\
$\begin{array}{l}\text { Area Business (\% total buildings } \\
\text { in the sub-district) }\end{array}$ & $6.72 \%$ & $3.24 \%$ \\
$\begin{array}{l}\text { Area Public(\% total buildings in } \\
\text { the sub-district) }\end{array}$ & $1.23 \%$ & \\
\hline
\end{tabular}

To control for spatial differences in both the analyses, data on the percentage of buildings used for housing, business, social and public are retrieved from the Dutch Central Bureau of Statistics (CBS Statline, 2016) and are matched to a charging station at the sub-district level. Information about the number of reserved parking spots and paid parking areas was provided by the municipality of The Hague. Variables that served as a proxy for charging station density were tried but were found to be insignificant.

\subsubsection{Free Parking}

To examine the effect of free parking (for EVs) on EV-charging behaviour we analyse charging data of the four major cities in the Netherlands (Amsterdam, Rotterdam, The Hague, Utrecht) in 2015 and 2016. Of these four cities, only the city of Utrecht has implemented a policy that allows free parking for EVs while they are charging. For this analysis, the same source is used as in the case of daytime charging in The Hague (see previous section). In this case, over 1.7 million charging sessions are selected. The charging session data were enriched with data on paid parking areas of all cities, which were matched to the GPS locations of the charging stations using the $s p$ package in R Studio (Bivand, Pebesma, \& Gomez-Rubio, 2013; Pebesma \& Bivand, 2005).

Table 2 shows the descriptive statistics of the selected charging sessions and the mean connection times for the various categories. The connection time of charging sessions was not normally distributed, but showed two peaks (of 0-4hours and 8-16 hours connection time or duration). As this 
would violate the assumptions of linear regression, the decision was made to recode the connection time (our dependent variable) into an ordinal variable and perform an ordinal regression analysis. To this end, the following categories were used: 1:0-6 hours; 2 : 6-16 hours; $3: 16-24$ hours; $24+$ hours.

Table 2 Descriptive statistics for analysis data free parking policy

\begin{tabular}{|c|c|c|c|}
\hline Variable & \% Of charge data & $\begin{array}{l}\text { Mean } \\
\text { Connection } \\
\text { time }\end{array}$ & $\begin{array}{l}\text { SD } \\
\text { Connection } \\
\text { time }\end{array}$ \\
\hline \multicolumn{4}{|l|}{ Cities } \\
\hline Utrecht & $13 \%$ & 10.59 & 11.79 \\
\hline Amsterdam & $47 \%$ & 10.83 & 19.83 \\
\hline Rotterdam & $22 \%$ & 10.29 & 27.39 \\
\hline The Hague & $17 \%$ & 10.38 & 18.43 \\
\hline Total sessions & $2,124,960$ & & \\
\hline Total & $100 \%$ & 10.60 & 20.76 \\
\hline Paid & $66 \%$ & 10.81 & 22.78 \\
\hline Free & $34 \%$ & 10.18 & 15.93 \\
\hline Utrecht & $13 \%$ & 10.59 & 11.79 \\
\hline Paid & $48 \%$ & 11.41 & 13.09 \\
\hline Free & $52 \%$ & 9.83 & 10.41 \\
\hline Amsterdam & $47 \%$ & 10.83 & 19.83 \\
\hline Paid & $85 \%$ & 10.89 & 20.72 \\
\hline Free & $15 \%$ & 10.51 & 13.55 \\
\hline Rotterdam & $22 \%$ & 10.29 & 27.39 \\
\hline Paid & $48 \%$ & 10.39 & 36.93 \\
\hline Free & $52 \%$ & 10.19 & 12.92 \\
\hline The Hague & $17 \%$ & 10.38 & 18.43 \\
\hline Paid & $54 \%$ & 10.54 & 12.22 \\
\hline Free & $46 \%$ & 10.18 & 23.77 \\
\hline \multicolumn{4}{|l|}{ Time of Day } \\
\hline Morning (5:00-10:00) & $15 \%$ & 6.54 & 13.83 \\
\hline Afternoon (10:00-16:00) & $30 \%$ & 8.17 & 23.64 \\
\hline Evening (16:00-22:00) & $46 \%$ & 13.02 & 18.57 \\
\hline Night (22:00 - 05:00) & $10 \%$ & 12.67 & 27.08 \\
\hline \multicolumn{4}{|l|}{ Part of the week } \\
\hline Week & $61 \%$ & 10.02 & 20.65 \\
\hline Weekend & $39 \%$ & 11.51 & 20.89 \\
\hline \multicolumn{4}{|l|}{ Year } \\
\hline 2015 & $38 \%$ & 10.64 & 23.65 \\
\hline \multirow[t]{2}{*}{2016} & $62 \%$ & 10.57 & 18.75 \\
\hline & Mean & SD & \\
\hline $\begin{array}{l}\text { Area Living (\% total } \\
\text { buildings in the sub- } \\
\text { district) }\end{array}$ & $48.58 \%$ & $23.00 \%$ & \\
\hline
\end{tabular}




\begin{tabular}{|lcc|}
\hline $\begin{array}{l}\text { Area Business (\% total } \\
\text { buildings in the sub- } \\
\text { district) }\end{array}$ & $6.72 \%$ & $10.79 \%$ \\
$\begin{array}{l}\text { Area Public(\% total } \\
\text { buildings in the sub- } \\
\text { district) }\end{array}$ & $1.23 \%$ & $3.24 \%$ \\
\hline
\end{tabular}

In the analysis the results are controlled for spatial-temporal differences as is common in parking literature (Kelly \& Clinch, 2009; Pu, Li, Ash, Zhu, \& Wang, 2017). The same spatial variables are used as in the daytime charging study; we expanded this set with dummy variables identifying each of the cities. The city of Amsterdam is used as reference level for these city level factors. In terms of temporal differences, the starting time of the charging session is used to derive the time of day and the day of the week in which the charging session takes place. The day of the week is dummy coded for week versus weekend days (Friday, Saturday, Sunday) in which weekdays are the reference level. For time of day, the evening serves as a reference. Additionally, the year was included as a control variable (with 2015 serving as the reference level).

\subsubsection{Purchaseintention}

It was hypothesized that public charging station policy of a city was mostly relevant for those that make most use of it. Those that have the possibility to install their own charging station at home are very unlikely to make use of the public infrastructure within the same city. Respondents for the stated preference study were therefore recruited among citizens that did not have their own parking facility and therefore required on-street parking. Respondents were recruited by distributing letters in the cities with an active charging infrastructure policy (Rotterdam, The Hague) and without such a policy (Leiden, Delft) with a request to participate in an online survey. Additionally, to preventa positive EV bias (Smith, Olaru, Jabeen, \& Greaves, 2017), people were recruited face to face with a similar paperversion of the stated preference study. The survey started with a question on whether or not the respondent had a drivers' license, a negative answer resulted in exclusion from the experiment.

Respondents were asked to perform 9 choice tasks in which they were asked to choose which car they would purchase. Data was collected using an online (112 respondents) and paper-and-pencil (37 respondents) totalling 149 useful responses and 1327 choice observations. Table 3 displays the demographics of the respondents.

Table 3 Demographic distribution of respondents

\begin{tabular}{|l|l|l|}
\hline Age & $<35$ years & $23 \%$ \\
& $35-65$ years & $57 \%$ \\
& $>65$ years & $20 \%$ \\
\hline Income & $<€ 25.000$ & $13 \%$ \\
& $€ 25.000-€ 45.000$ & $17 \%$ \\
& $>€ 45.000$ & $51 \%$ \\
& Unknown & $19 \%$ \\
\hline Gender & Male & $70 \%$ \\
\hline
\end{tabular}




\begin{tabular}{|l|l|l|}
\hline & Female & $30 \%$ \\
\hline Education level & Highereducation & $70 \%$ \\
& College & $24 \%$ \\
& High School & $6 \%$ \\
\hline Full Employment & Yes & $62 \%$ \\
& No & $38 \%$ \\
\hline No. of cars & 0 & $11 \%$ \\
& 1 & $64 \%$ \\
& 2 & $19 \%$ \\
& $2+$ & $6 \%$ \\
\hline
\end{tabular}

The demographics show that males, higher educated and high income respondents are over represented in comparison to the general population (CBS, 2016). Employment rate of the respondents is relatively low but can be explained by a significant number of elderly ( $>65$ years) that participated in the experiment. $11 \%$ of respondents answered that they did not own a car, but these respondents did indicate that they considered buying a car in the next 3 years. These numbers suggest that sufficient heterogeneity exists to identify possible socio-demographic interactions. Deviations from socio-demographic distributions in the population at large imply that estimation results should not be translated directly into population wide estimates of policy effects. Since the aim of this study was to identify the existence and size of policy effects, rather than attempting to predict market shares for EVs in the population, we consider our data to be sufficient.

\section{Results}

\subsection{Daytime charging policy: Effect on charging behaviour}

Figure 4 shows the average occupancy ratio over the day during the period January 2014 -August 2015 for the two categories of charging stations. It can be seen that the average occupancy (by EVs) is relatively low, i.e., $15 \%$ during the daytime and $25 \%$ during the night time. It can also be observed that charging stations with daytime charging policies have nearly the same occupation throughout the day and higher occupancy during evening and night times. For charging stations without daytime charging policies a more distinct profile is visible with higher occupancy in the night and a lower occupancy during day time. This clearly suggests that the implemented policy is effective in reducing usage of charging stations as mere (free) parking spots by EV-owners, especially during the evening and night time. 


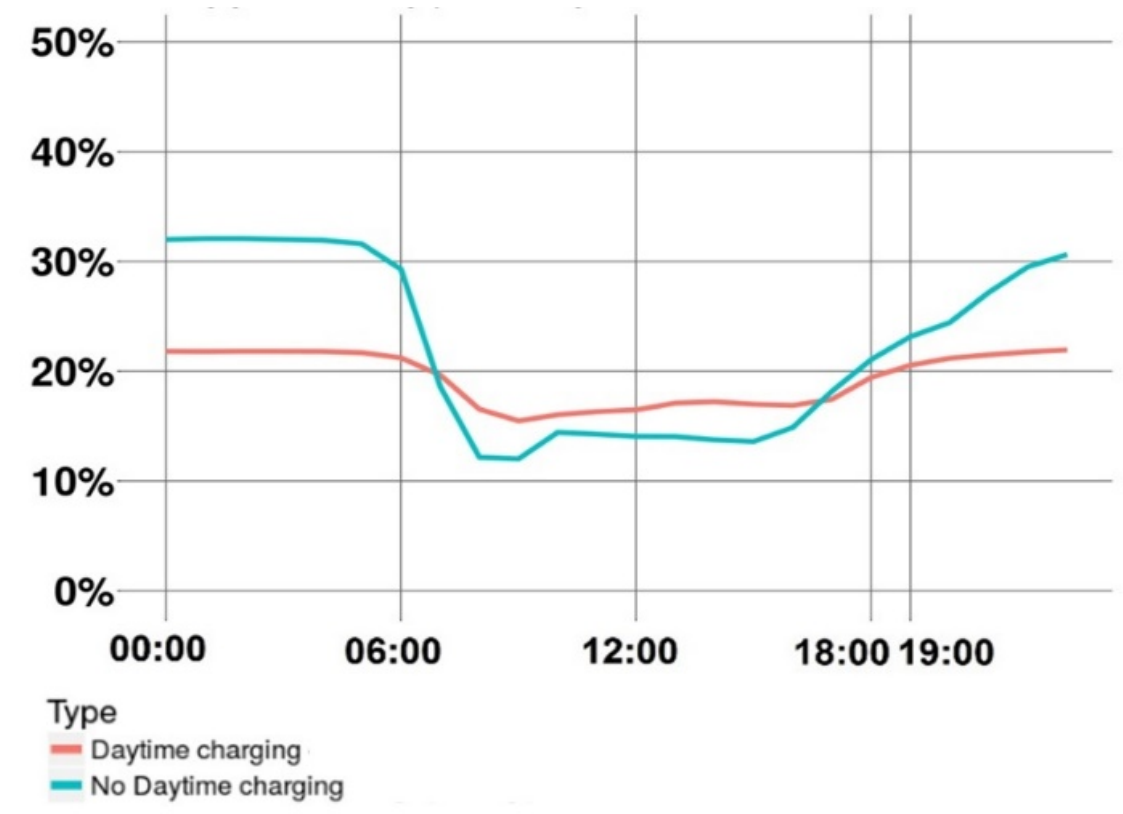

Figure 4 Charging station occupancy throughout the day for daytime and no daytime charging for 2014- August 2015

To assess whether the day-time charging policy has a statistically significant effect on the (average) occupancy ratio, while controlling for possible confounding factors, a linear regression is performed using the change in occupancy rate between $7 \mathrm{PM}$ and midnight as the dependent variable. A positive (negative) sign for an estimated parameter implies that an increase in the associated variable leads to an increase (decrease) in the increase in occupancy rate. Expectations - based on intuition and inspection of Figure 4 - are that there will be a negative effect associated with the Daytime charging policy. The results of the linear regression (Table 4) show that charging stations which have the daytime charging policy implemented have, as expected, less increase in occupancy rates between 19:00 and 0:00, compared to those stations without this policy. The model shows that implementation of the daytime charging policy leads to 3.6 percentage points less increase in occupancy, when controlling for other factors; a modest but significant effect. This result implies that the policy reaches the intended effect which is making room for non-EV drivers looking for a parking spot. Although parking sessions of these vehicles are measured indirectly the results clearlysuggest that these parking spots have become inaccessible for EV drivers because they are occupied by nonEVs.

Table 4 Results of linear regression on charging station occupancy increase between 19:00 and 0:00 before September 2015

\begin{tabular}{|llll|}
\hline & Estimate & Std. Error & t value \\
Intercept & 0.008 & 0.014 & 0.62 \\
Daytime charging & $-0.036^{*}$ & 0.006 & -5.79 \\
Area living & $0.039^{*}$ & 0.019 & 2.01 \\
Area business & -0.051 & 0.037 & -1.38 \\
Area public & $-0.191^{*}$ & 0.086 & -2.21 \\
2 Dedicated parking spots & $0.029^{*}$ & 0.006 & 4.79 \\
Free parking & 0.006 & 0.006 & 1.06 \\
$\mathbf{R}^{2}$ & 0.189 & & \\
\hline
\end{tabular}


*significant at the $p<0.05$ level

While not of direct interest in the present study, the effects of the control variables are plausible. For example, in areas with more buildings dedicated to housing the occupancy increase between 19:00 and 0:00 is larger. This can be explained by the fact that EV drivers arrive at home after work in these hours. Areas with more buildings dedicated to businesses have no significant effect on occupancy increase and areas with a more public function show a negative impact on occupancy increase in the evening. This effect is plausible as such building often have opening hours during the day. If the charging station has two dedicated parking spots for electric vehicles this positively influences the increase in occupancy rate. This is al so a logical effect, as availability could be limited by ICE vehicles parked next to the charging station. No significant effect was found for free parking, which is also plausible as most users between 19:00 and 0:00 are residents with a parking permit, cancelling out the effect of parking prices.

\subsection{Free parking policy: effect on charging behaviour}

The results of the ordinal regression are shown in Table 5. A positive (negative) parameter suggests that an increase in the associated variable leads to an increase (decrease) in connection duration. Focussing on the free parking policy, the attention should go to the interaction between the 'city of Utrecht'-dummy coefficient and the paid parking-coefficient. Within this particular paid parking area, free parking for EVs is offered. The fact that the interaction is positive and significant indicates that connection times in this area are longer, compared to paid parking areas in other cities. In other words: offering free parking for EV s in a zone which requires paid parking for conventional cars results in longerEV-connection times; this is in line with expectations. The results also show that the effect of paid parking Utrecht is larger than the paid parking parameter, showing that connection duration of sessions in Utrecht is actually longer inside paid parking areas than outside. An explanation for this finding is that, although free parking for EVs applies in both areas, EVs are more restricted to the spot at the charging station because paid parking applies at parking spots next to the charging stations. Therefore, users are de-incentivised to move their car once it is fully charged because they have to pay a parking fee if they move their car.

Table 5 Results of Ordinal regression on connection duration

\begin{tabular}{|lclc|}
\hline & Estimates & Std. err. & t-value \\
Paid Parking & $-0.136^{*}$ & 0.005 & -24.89 \\
Cities & & & \\
Den Haag & $-0.116^{*}$ & 0.007 & -16.84 \\
Rotterdam & $0.026^{*}$ & 0.006 & 4.14 \\
Utrecht & $-0.129 *$ & 0.007 & -18.10 \\
Time & & & \\
Afternoon & $-1.790^{*}$ & 0.004 & -468.83 \\
Night & $0.216^{*}$ & 0.004 & 57.35 \\
Morning & $-1.219 *$ & 0.004 & -312.50 \\
Weekend & $-0.017 *$ & 0.003 & -6.19 \\
Year 2016 & $-0.009 *$ & 0.003 & -3.39 \\
Spatial characteristics & & & \\
\hline
\end{tabular}




\begin{tabular}{|lllc|}
\hline Area living & $0.730^{*}$ & 0.007 & 98.23 \\
Area business & 0.019 & 0.015 & 1.33 \\
Area public & $0.340 *$ & 0.047 & 7.28 \\
Interactions & & & \\
Paid Parking * The Hague & $0.191^{*}$ & 0.009 & 22.43 \\
Paid Parking * Rotterdam & $0.045^{*}$ & 0.008 & 5.75 \\
Paid Parking * Utrecht (Free) & $0.298^{*}$ & 0.009 & 32.573 \\
Intercepts & & & \\
0-6 -> 6-16 hours & $-0.566 *$ & 0.007 & -83.82 \\
6-16-hours -> 16-24hours & $0.063^{*}$ & 0.007 & 9.349 \\
16-24 -> 24+ hours & $2.711^{*}$ & 0.007 & 377.29 \\
\hline
\end{tabular}

*Significant at the $p<0.05$ level

The controlling factors show that in general parking in paid parking areas is shorter than in non-paid parking areas, which is in line with general parking theory although the effect is much smaller than expected, most likely because a large number of regular users (which have parking permits) make use of the charging infrastructure. Small differences exists between the cities, for which several reasons can exist, e.g. charging infrastructure roll-out intensity and city lay-out. Time factors play an important role in determining the length of the charging session. Charging sessions starting in the evening and night last much longer because these cars stay connected overnight. In the afternoon a lot of short sessions take place, while in the morning such sessions are combined with 'workplace' charging resulting in slightly longer sessions than in the afternoon. Differences between week and weekend session and in 2015 and 2016 are minimal. Areas with a focus on housing have longer sessions, most likely because users al so stay here overnight. Buildings dedicated to business have no significant effect on charging times while built environment with a public function leads surprisingly to longer charging times.

\subsection{Purchase intention}

In Table 6 the results of the mixed logit model are presented. All variables are modelled as continuous variables as this specification provided the best model fit (adjusted for parsimony). Interactions with several socio-demographic variables have been tested but since these did not provide significant results they are left out of the final model (note that this too, suggests that the fact that our respondents are not fully representative of the population in terms of sociodemographic dimensions, is inconsequential). A multinomial model has been tested as well (Final LL $=-1389.428$ ) but the mixed logit model provided the best fit, suggesting that there were high levels of heterogeneity in unobserved utility.

Placement strategy of charging stations is the policy with the largest effect on FEV and PHEV purchase intention in the model estimation. It is effect is nearly twice as big as the parking fee policy and almost three times larger than the effect of availability policies. The parameters show that having to share the public charging station with more owners has a negative impact on FEV and PHEV purchase intention. The effect was found to be more than twice as big for FEV as for PHEV. This 
makes sense as certainty about the availability of a charging station at home is less important for PHEVs as they have a gasoline back-up. The parameter for the parking fee policy on FEV is significant and negative, showing that offering cost reductions in parking fees is a positive influence on FEV purchase intention. Such an effect was, however, not found for the PHEV which is in contrast with our expectations; it was expected that PHEV drivers would be relatively sensitive to financial policies. The results give an indication that offering free parking could be more effective to enhance sales of FEVs compared to sales of PHEVs. The availability policy, which included the daytime policy has a significant and positive sign for the FEV but is not significant for the PHEV. This indicates that making parking spots next to charging stations exclusively available for EV s could enhance EV sales. The model shows that restricting this exclusivity, by implementing daytime charging or allowing ICE vehicles to park next to charging stations, reduces the purchase intention for FEVs. Such an effect is not found for PHEVs which could be explained by the same reasons as in the placement policy; PHEVs have a back-up option if the charging station is not available.

Constants for the EV are large, mainly because price is not included in the utility function for the gasoline car (as it did not vary across gasoline car alternatives). The sigmas for both EV and conventional are large compared to the constants indicating that base preferences for either electric or gasoline driven cars vary across respondents significantly. Separate beta's were estimated for the price for FEV and PHEV (-0.224 and -0.209 respectively) but this gave a reduction in model fit (Final $\longrightarrow$ $=-863.268$ ). As the beta's did not differ a lot a single price parameter was estimated. The results show that price plays an important factor in the purchase decision as was hypothesized. Separate betas for the range were estimated as different effects were expected. The results show that range for FEV is significant and positive, implying that purchase intention increases with range. The range parameter for PHEV s is however not significant. This was expected as we hypothesized that PHEV users mainly use their car for short (e.g. home-work) distances and range therefore would not be important. 
Table 6 Results of Mixed Logit Model

\begin{tabular}{|c|c|c|c|c|c|c|}
\hline \multirow[t]{2}{*}{ Estimates } & \multirow[t]{2}{*}{ Value } & \multirow[t]{2}{*}{$\begin{array}{l}\text { Rob. } \\
\text { Std. err. }\end{array}$} & \multicolumn{2}{|c|}{$\begin{array}{c}90 \% \text { confidence } \\
\text { interval }\end{array}$} & \multirow[t]{2}{*}{$\begin{array}{l}\text { Rob.t- } \\
\text { value }\end{array}$} & \multirow[t]{2}{*}{ p-value } \\
\hline & & & Low & High & & \\
\hline Constant EV & 6.410 & 1.000 & -1.392 & 1.250 & 6.39 & 0.00 \\
\hline Constant Conventional & -0.071 & 0.800 & 4.765 & 8.055 & -0.09 & 0.93 \\
\hline Price & -0.217 & 0.026 & -0.260 & -0.174 & -8.34 & 0.00 \\
\hline Range EV & 0.005 & 0.001 & 0.003 & 0.007 & 4.42 & 0.00 \\
\hline Range PHEV & 0.000 & 0.004 & -0.006 & 0.007 & 0.08 & 0.94 \\
\hline Placement EV & -1.110 & 0.203 & -1.444 & -0.776 & -5.44 & 0.00 \\
\hline Placement PHEV & -0.485 & 0.181 & -0.783 & -0.187 & -2.68 & 0.01 \\
\hline Parking Fee EV & -0.617 & 0.185 & -0.921 & -0.313 & -3.34 & 0.00 \\
\hline Parking Fee PHEV & -0.089 & 0.158 & -0.350 & 0.170 & -0.57 & 0.57 \\
\hline Availability EV & 0.448 & 0.188 & 0.139 & 0.757 & 2.39 & 0.02 \\
\hline Availability PHEV & 0.055 & 0.167 & -0.219 & 0.330 & 0.33 & 0.74 \\
\hline Sigma EV & 3.940 & 0.606 & 2.943 & 4.937 & 6.51 & 0.00 \\
\hline Sigma Conventional & 3.900 & 0.428 & 3.196 & 4.604 & 9.10 & 0.00 \\
\hline Number of observations: & 1327 & & & & & \\
\hline Number of individuals: & 149 & & & & & \\
\hline Null log likelihood & -1457.859 & & & & & \\
\hline Final log likelihood & -860.243 & & & & & \\
\hline$P^{2}$ & 0.408 & & & & & \\
\hline
\end{tabular}

The estimate for the Willingness-To-Pay (WTP) for range $(€ 22,40 / \mathrm{km})$ is at the low end of the spectrum observed in the meta-study performed by Dimitropoulos, Rietveld, \& Ommeren (2013). Dimitropoulos, Rietveld, \& Ommeren however also included different type of alternative fuel vehicles and includes studies that date back to the 1970s. Due to advances in battery prices and more EVs on the road with greater range making range could have become a less valuable attribute of the electric car. Our results are in line with more recent findings in Germany (Hackbarth \& Madlener, 2013) which have found a WTP of $€ 16-€ 33$ per km of electricrange. WTP for sharing a charging station with one EV less is $€ 2248-€ 2557$ which is somewhat above the price of installing a private charging station of $+/-€ 1500$ (Madina et al., 2016). The willingness to pay for free parking ( $€ 1.421$ ) far exceeds the costs of a parking permit in the study areas (+/- €150 annually) (Municipality of Leiden, 2017). Respondents could have taken into account that they do not have to pay for this permit for several years and that free parking could be applicable in other cities as well.

\section{Conclusion and policy implications}

This paper has investigated the research gap consisting of the cross-links between the effects of EV purchase and charging policies. Our literature review shows that a growing body of research has shed 
light on the factors determining the purchase (intention) of prospective owners for EVs and that more real world information is becoming available on how the charging of EVs can be controlled by charging behaviour management schemes. Research on the cross-links between these policy-effects has however been missing so far. This paper has filled this gap by analysing the effects of two case studies, concerning daytime charging and free parking, on both charging behaviour of EV-owners and on purchase intentions of non-owners, through an unique combination of natural and stated choice studies. We have focused on the context of public charging stations in dense urban areas.

Regarding daytime charging policies, our findings indicate that this policy is indeed effective in decreasing parking pressure due to underutilised EV-charging stations. Occupation of charging points in the evening appears to be lower where daytime charging policies are implemented. The results of our choice experiment however shows that creating uncertainty about the availability of charging stations near home, through e.g. daytime charging, reduces the purchase intention for full EVs.

Concerning free parking policies (for EVs), our results show that offering free parking has a positive effect on the purchase intention of full EVs. However, our analysis of this policy as implemented in the city of Utrecht and its effect on the connection duration of charging sessions shows a possible negative side-effect of this policy. Compared to other cities and even in free parking areas, we find that charging sessions in Utrecht were considerably longer than elsewhere, also when controlling for a variety spatial-temporal characteristics.

The results of our case studies show that investigating these cross-links between EV purchase policies, EV charging policies and there intended effects is a relevant subject of study, as these crosseffects may be non-trivial. The case study concerning free parking policy shows that, on the one hand, the policy could have a positive effect on purchase intention, while, on the other hand, it also influences the connection duration of charging sessions, which could lead to inefficient use of charging stations. Vice versa, this paper shows through a case study of daytime charging that controlling charging behaviour (through charging demand management measures) can be effective but that such a restrictive policy negatively influences EV-purchase intentions. Although the crosseffects of such policies do not appear to be dominant in either determining charging behaviour or purchase intention, they are too important to ignore by policy makers who aim to design policies that are effective at one level (e.g. stimulating EV-ownership) without having negative side effect at another level (e.g. parking pressure). Indeed, policy makers in cities throughout the world are seeking for effective ways to promote EVs and at the same time manage EV charging infrastructure. This research shows that policy makers should not only focus on the direct effects on the intended policy but also take into account possible (negative) side effects. The presented case studies, each evaluated with an unique database on charging behaviour, show that these side effects do exist and therefore should be taken into account when evaluating the effect of proposed or implemented policies.

Cross-links between policies are of course not limited to charging behaviour control and purchase policies. As an example such policies may also interfere with grid management, which could become a major issue in the context of a large scale introduction of EVs. For example, daytime charging policies could encourage EV drivers to start their charging session earlier to ensure they have a charging station available; and charging sessions that otherwise would have started later in the evening could align with a peak in electricity demand in the late afternoon and early morning. 
Although we encourage further research where interests of several stakeholders such as the mobility and energy sector have to be aligned, we consider such wider implications and cross-links outside of the scope of this paper.

This paper has also contributed into insights in EV charging behaviour and purchase in dense urban areas where (prospective) owners depend on public charging infrastructure. Current literature indicates that home and workplace charging are the dominant modes. Much focus is however on the planning of (fast) charging for longer trips, home and workplace charging for those that rely on public charging remains an underexposed field of study. This focus can be explained as currently the majority of EV owners belongs to a high income group which often has private charging infrastructure. If EVs however reach the masses, those that depend on on-street parking should be taken into account when planning for the charging infrastructure. Especially policy makers in cities, where on-street parking is more common, shall face the dilemma of how to organise this charging infrastructure efficiently. The results presented in this paper not only indicate the effect of the tested policies but also give an indication of how these charging stations are used in general.

Potential pitfalls in our analyses that could be improved in future work lie in determining the effect of policy measures on the purchase intention. Note that given the set-up of the experiment, which only considers parking policies and a limited amount of vehicle characteristics, we cannot rule out that the salience of such policies may have been overemphasized in the eyes of participants. A twostep approach in which respondents would first (i.e. in stage one) are asked to evaluate the choice alternatives without the policy context, could help in reducing any possible bias in future work. Furthermore, inclusion of more variables, and more variation in vehicle-characteristics which in our study were being held constant, could provide a further means to eliminate hypothetical bias. The aim of this paper was to indicate that such policies do have a substantial effect on purchase intention and further research, both with stated and revealed preferences, could further reveal the importance of these policies compared to other factors. The stated preference study was aimed at those respondents that rely on on-street charging facilities; this focus was motivated by pointing out that such a group is currently underrepresented in studies. Note also that the case study policies we consider would have most effect on this subset of the population. Further research could look into effects of policies for those EV-users that do have home-charging possibilities and potentially set up a comparison between these groups in terms of their response to charging policies. The natural experiments benefited from situations which allowed comparisons of several policies measures on aspects of charging behaviour. However, also these case studies were not without limitations. The daytime charging experiment lacked data from actual gasoline cars parking in the freely available spots because of the policy. The parking behaviour of these vehicles had to be derived from the absence of EVs in this spot. Despite these limitations we believe that this paper has provided compelling evidence that the cross-links between the effects of EV-charging policies are a relevant topic of study and should be the subject of more future research.

\section{Acknowledgements}

We are grateful for the funding provided by the Sia Raak for the IDOLaad project of which this research is part of. We are also grateful for the cooperation of the participating municipalities and especially with the municipality of The Hague for providing the additional data relevant to daytime charging. 


\section{References}

Axsen, J., \& Kurani, K. S. (2012). Who can recharge a plug-in electric vehicleat home ? Transportation Research Part D: Transport and Environment, 17(5), 349-353. http://doi.org/10.1016/j.trd.2012.03.001

Bailey, J., Miele, A., \& Axsen, J. (2015). Is awareness of public charging associated with consumer interest in plug-in electric vehicles ? Transportation Research Part D: Transport and Environment, 36, 1-9. http://doi.org/10.1016/j.trd.2015.02.001

Bakker, S., Maat, K., \& van Wee, B. (2014). Stakeholders interests, expectations, and strategies regarding the development and implementation of electric vehicles: The case of the Netherlands. Transportation Research Part A: Policy and Practice, 66(1), 52-64. http://doi.org/10.1016/j.tra.2014.04.018

Bierlaire, M. (2003). BIOGEME: A free package for the estimation of discrete choice models. In Proceedings of the 3rd Swiss Transportation Research Conference. Ascona, Switzerland.

Bivand, R. S., Pebesma, E. J., \& Gomez-Rubio, V. (2013). Applied spatial data analysis with R (Second). New York, NY: Springer.

Bjerkan, K. Y., Nørbech, T. E., \& Nordtømme, M. E. (2016). Incentives for promoting Battery Electric Vehicle (BEV) adoption in Norway. Transportation Research Part D: Transport and Environment, 43, 169-180. http://doi.org/10.1016/j.trd.2015.12.002

Carley, S., Krause, R. M., Lane, B. W., \& Graham, J. D. (2013). Intent to purchase a plug-in electric vehicle :A survey of early impressions in large US cites. Transportation Research Part D: Transport and Environment, 18(18), 39-45. http://doi.org/10.1016/j.trd.2012.09.007

CBS Statline. (2016). Kerncijfers wijken en buurten 2016. Retrieved April 18, 2016, from https://www.cbs.nl/nl-nl/maatwerk/2016/30/kerncijfers-wijken-en-buurten-2016

Cherchi, E. (2017). A stated choice experiment to measure the effect of informational and normative conformity in the preference for electric vehicles. Transportation Research Part A: Policy and Practice, 100, 88-104. http://doi.org/10.1016/j.tra.2017.04.009

Chorus, C. G., Koetse, M. J., \& Hoen, A. (2013). Consumer preferences for alternative fuel vehicles: Comparing a utility maximization and a regret minimization model. Energy Policy, 61, 901-908. http://doi.org/10.1016/j.enpol.2013.06.064

Coffman, M., Bernstein, P., \& Wee, S. (2016). Electric vehicles revisited : a review of factors that affect adoption. Transport Reviews, 1-15. http://doi.org/10.1080/01441647.2016.1217282

Daina, N. (2014). Modelling Electric vehicle use and charging behaviour. PhD Thesis at Imperial College London.

Egbue, O., \& Long, S. (2015). Barriers to widespread adoption of electric vehicles : An analysis of consumer attitudes and perceptions. Energy Policy, 48(2012), 717-729. http://doi.org/10.1016/j.enpol.2012.06.009

Ensslem, A., Jochem, P., Schäuble, J., \& Babrowski, S. (2013). User Acceptance of Electric Vehicles in the French-German Transnational Context. In 13th WCTR, July 15-18, 2013-Rio de Janeiro, Brazil (pp. 1-23). Retrieved from http://www.wctrs-society.com/wp/wpcontent/uploads/abstracts/rio/selected/1183.pdf 
Fearnley, N., Pfaffenbichler, P., Figenbaum, E., \& Jellinek, R. (2015). E-vehicle policies and incentives assessment and recommendations ( $\mathrm{T} \varnothing \mathrm{I}$ report). Retrieved from https://www.toi.no/getfile.php?mmfileid=41187

Frade, I., Ribeiro, A., Gonçalves, G., \& Antunes, A. (2011). Optimal Location of Charging Stations for Electric Vehicles in a Neighborhood in Lisbon, Portugal. Transportation Research Record: Journal of the Transportation Research Board, 2252, 91-98. http://doi.org/10.3141/2252-12

Franke, T., \& Krems, J. F. (2013a). Understanding charging behaviour of electric vehicle users. Transportation Research Part F: Traffic Psychology and Behaviour, 21(2013), 75-89. http://doi.org/10.1016/j.trf.2013.09.002

Franke, T., \& Krems, J. F. (2013b). What drives range preferences in electric vehicle users? Transport Policy, 30, 56-62. http://doi.org/10.1016/j.tranpol.2013.07.005

Gnann, T., \& Plötz, P. (2015). A review of combined models for market diffusion of alternative fuel vehicles and their refueling infrastructure. Renewable and Sustainable Energy Reviews, 47, 783793. http://doi.org/10.1016/j.rser.2015.03.022

Hackbarth, A., \& Madlener, R. (2013). Consumer preferences for al ternative fuel vehicles : A discrete choice analysis. Transportation Research Part D: Transport and Environment, 25, 5-17. http://doi.org/10.1016/j.trd.2013.07.002

Hagman, J., Stier, J. J., \& Susilo, Y. (2016). Total cost of ownership and its potential implications for battery electric vehicle diffusion. Research in Transportation Business \& Management, 18, 1117. http://doi.org/10.1016/j.rtbm.2016.01.003

Hardman, S., Chandan, A., Tal, G., \& Turrentine, T. (2017). The effectiveness of financial purchase incentives for battery electric vehicles $-\mathrm{A}$ review of the evidence. Renewable and Sustainable Energy Reviews, 80(March), 1100-1111. http://doi.org/10.1016/j.rser.2017.05.255

Hardman, S., Tal, G., Turrentine, T., Axsen, J., Beard, G., Daina, N., ... Pontes, J. (2017). Driving the Market for Plug-in Vehicles - Developing PEV Charging Infrastructure for Consumers Lessons from Academic Research \& Empirical Data, (October).

Helmus, J., \& van den Hoed, R. (2015). Unraveling User Type Characteristics : Towards a Taxonomy for Charging Infrastructure. EVS28 International Electric Vehicle Symposium and Exhibition, 116.

Hoed, R. Van Den, Helmus, J. R., Vries, R. De, \& Bardok, D. (2014). Data analysis on the public charge infrastructure in the city of Amsterdam. In EVS27 Symposium, Barcelona, Spain, November 1720, 2013 (pp. 1-10). http://doi.org/10.1109/EVS.2013.6915009

Hoen, A., \& Koetse, M. J. (2014). A choice experiment on al ternative fuel vehicle preferences of private car owners in the Netherlands. Transportation Research Part A: Policy and Practice, 61, 199-215. http://doi.org/10.1016/j.tra.2014.01.008

Idaho National Laboratory. (2015a). Plugged In: How Americans Charge Their Electric Vehicles, 1-24. Retrieved from https://avt.inl.gov/sites/default/files/pdf/arra/SummaryReport.pdf

Idaho National Laboratory. (2015b). What Use Patterns Were Observed for Plug-In Electric Vehicle Drivers at Publicly Accessible Alternating Current Level 2 Electric Vehicle Supply Equipment Sites ?, 1-4.

International Energy Agency. (2016). Global EV Outlook 2016: Beyond one million electric cars. 
Jabeen, F., Olaru, D., Smith, B., Braunl, T., \& Speidel, S. (2013). Electric vehicle battery charging behaviour: Findings from a driver survey. 36th Australasian Transport Research Forum (ATRF), Brisbane, Queensland, Australia.

Jakobsson, N., Gnann, T., Plötz, P., Sprei, F., \& Karlsson, S. (2016). Are multi-car households better suited for battery electric vehicles? - Driving patterns and economics in Sweden and Germany. Transportation Research Part C: Emerging Technologies, 65, 1-15. http://doi.org/10.1016/j.trc.2016.01.018

Krupa, J. S., Rizzo, D. M., Eppstein, M. J., Lanute, D. B., Gaalema, D. E., Lakkaraju, K., \& Warrender, C. E. (2014). Analysis of a consumer survey on plug-in hybrid electric vehicles. Transportation Research Part A, 64, 14-31. http://doi.org/10.1016/j.tra.2014.02.019

Latinopoulos, C., Sivakumar, A., \& Polak, J. (2017). Modeling Electric Vehicle Charging Behavior: What Is the Relationship Between Charging Location, Driving Distance, and Range Anxiety? Transportation Research Board, 96th AnnualMeeting.

Li, S., Tong, L., Xing, J., \& Zhou, Y. (2017). The Market for Electric Vehicles : Indirect Network Effects and Policy Design. Journal of the Association of Environmental and Resource Economists, 4(1), 89-133.

Liao, F., Molin, E., \& Wee, B. Van. (2015). Consumer Preferences for Electric Vehicles : a Literature Review. Transport Reviews, 1-24.

Liu, J. (2012). Electric vehicle charging infrastructure assignment and power grid impacts assessment in Beijing. Energy Policy, 51, 544-557. http://doi.org/10.1016/j.enpol.2012.08.074

Madina, C., Zamora, I., \& Zabala, E. (2016). Methodology for assessing electric vehicle charging infrastructure business models. Energy Policy, 89, 284-293.

http://doi.org/10.1016/j.enpol.2015.12.007

Mersky, A. C., Sprei, F., Samaras, C., \& Qian, Z. (Sean). (2016). Effectiveness of incentives on electric vehicle adoption in Norway. Transportation Research Part D, 46, 56-68.

http://doi.org/10.1016/j.trd.2016.03.011

Molin, E. J. E., \& Timmermans, H. J.P. (2010). Context dependent stated choice experiments: The case of train egress mode choice. Journal of Choice Modelling, 3(3), 39-56. http://doi.org/10.1016/S1755-5345(13)70013-7

Morrissey, P., Weldon, P., \& Mahony, M. O. (2016). Future standard and fast charging infrastructure planning : An analysis of electric vehicle charging behaviour. Energy Policy, 89, 257-270. http://doi.org/10.1016/j.enpol.2015.12.001

Municipality of Leiden. (2017). Parkeertarieven voor bewoners. Retrieved June 8, 2017, from https://gemeente.leiden.nl/themas/zones-tarieven/parkeertarieven/bewoners/

Nykvist, B., \& Nilsson, M. (2015). Rapidly falling costs of battery packs for electric vehicles. Nature Climate Change, 5, 329-332.

Pebesma, E. J., \& Bivand, R. S. (2005). Classes and methods for spatial data in R. R News, 5(2).

Rangaraju, S., De Vroey, L., Messagie, M., Mertens, J., \& Van Mierlo, J. (2015). Impacts of electricity mix, charging profile, and driving behavior on the emissions performance of battery electric vehicles: A Belgian case study. Applied Energy, 148(X), 496-505.

http://doi.org/10.1016/j.apenergy.2015.01.121 
Razeghi, G., Carreras-sospedra, M., Brown, T., Brouwer, J., Dabdub, D., \& Samuelsen, S. (2016). Episodic air qual ity impacts of plug-in electric vehicles. Atmospheric Environment, 137, 90-100. http://doi.org/10.1016/j.atmosenv.2016.04.031

Rezvani, Z., Jansson, J., \& Bodin, J. (2015). Advances in consumer electric vehicle adoption research : A review and research agenda. Transportation Research Part D, 34, 122-136. http://doi.org/10.1016/j.trd.2014.10.010

Robinson, a. P., Blythe, P. T., Bell, M. C., Hübner, Y., \& Hill, G. a. (2013). Analysis of electric vehicle driver recharging demand profiles and subsequent impacts on the carbon content of electric vehicle trips. Energy Policy, 61, 337-348. http://doi.org/10.1016/j.enpol.2013.05.074

Sathaye, N., \& Kelley, S. (2013). An approach for the optimal planning of electric vehicle infrastructure for highway corridors. Transportation Research Part E: Logistics and Transportation Review, 59, 15-33. http://doi.org/10.1016/j.tre.2013.08.003

Schroeder, A., \& Traber, T. (2012). The economics of fast charging infrastructure for electric vehicles. Energy Policy, 43, 136-144. http://doi.org/10.1016/j.enpol.2011.12.041

Shahraki, N., Cai, H., Turkay, M., \& Xu, M. (2015). Optimal locations of electric public charging stations using real world vehicle travel patterns. Transportation Research Part D: Transport and Environment, 41, 165-176. http://doi.org/10.1016/j.trd.2015.09.011

Shoup, D. (2005). The high cost of free parking. American Planning Association.

Sierzchula, W., Bakker, S., Maat, K., \& Wee, B. Van. (2014). The in fluence of financial incentives and other socio-economic factors on electric vehicle adoption. Energy Policy, 68, 183-194. http://doi.org/10.1016/j.enpol.2014.01.043

Smith, B., Olaru, D., Jabeen, F., \& Greaves, S. (2017). Electric vehicles adoption: Environmental enthusiast bias in discrete choice models. Transportation Research Part D: Transport and Environment, 51, 290-303. http://doi.org/10.1016/j.trd.2017.01.008

Speidel, S., Jabeen, F., Olaru, D., \& Harries, D. (2012). Analysis of Western Australian Electric Vehicle and Charging Station Trials, (lea 2011).

Spoelstra, J. C., \& Helmus, I. J. (2015). Public charging infrastructure use in the Netherlands : A rollout - strategy assessment. European Battery, Hybrid and Fuel Cell Electric Vehicle Congress, 1-10.

Sun, X. H., Yamamoto, T., \& Morikawa, T. (2016). Fast-charging station choice behavior among battery electric vehicle users. Transportation Research Part D: Transport and Environment, 46, 26-39. http://doi.org/10.1016/j.trd.2016.03.008

Toronto Atmospheric Fund. (2015). Fleetwise ev300. Retrieved from http://taf.ca/wpcontent/uploads/2014/09/FleetWise-EV300-Findings-Report-16-June-2015.pdf

Train, K. (2009). Discrete Choice Methods with Simulation (2nd ed.). New York, NY: Cambridge University Press.

Wardle, J. (2015). The rapid charge network. In European Battery, Hybrid and Fuel Cell Electric Vehicle Congress. Brussels.

Wen, Y., Mackenzie, D., \& Keith, D. (2015). Modeling charging choices of BEV owners using stated preference data. EVS 28, KINTEX, Korea.

Wirges, J. (2016). Planning the Charging Infrastructurefor Electric Vehicles in Cities and Regions 
(Doctoraldissertation). Karlsruher Institut für Technologie.

Xu, M., Meng, Q., Liu, K., \& Yamamoto, T. (2017). Joint charging mode and location choice model for battery electric vehicle users. Transportation Research Part B, 103, 68-86.

http://doi.org/10.1016/j.trb.2017.03.004

Yu, H., \& Mackenzie, D. (2016). Modeling Charging Choices of Small-Battery Plug-In Hybrid Electric Vehicle Drivers by Using Instrumented Vehicle Data. Transportation Research Record: Journal of the Transportation Research Board, 2572, 56-65. http://doi.org/10.3141/2572-07

Zhang, L., Shaffer, B., Brown, T., \& Samuelsen, G. S. (2015). The optimization of DC fast charging deployment in California. Applied Energy Journal, 157, 111-122. http://doi.org/10.1016/j.apenergy.2015.07.057

Zoepf, S., MacKenzie, D., Keith, D., \& Chernicoff, W. (2013). Charging choices and fuel displacement in a large-scale plug-in hybrid electric vehicle demonstration. Transportation Research Record: Journal of the Transportation Research Board, No. 2385, 1-10.

Appendix A: List of additional information provided in choice tasks

\begin{tabular}{|llll|}
\hline & Electric Vehicle & Plug-in Hybrid Vehicle & Conventional Vehicle \\
Range Gasoline & - & $600 \mathrm{~km}$ & $750 \mathrm{~km}$ \\
Fuel price per km & $€ 0,04 / \mathrm{km}$ & $€ 0,07 / \mathrm{km}$ & $€ 0,10 / \mathrm{km}$ \\
Road tax & $€ 0 /$ year & $€ 450 / \mathrm{year}$ & $€ 450 / \mathrm{year}$ \\
Charging speed home/work & $25 \mathrm{~km}$ range/hour & $25 \mathrm{~km}$ range/hour & - \\
Charging speed fast charging & $300 \mathrm{~km}$ range/hour & - & - \\
\hline
\end{tabular}

